\title{
Matrix Metalloproteinase 1 Measurement
}

National Cancer Institute

\section{Source}

National Cancer Institute. Matrix Metalloproteinase 1 Measurement. NCI Thesaurus. Code C80192.

The determination of the amount of matrix metalloproteinase 1 present in a sample. 